\title{
Religião e Espiritualidade no curso de Psicologia: revisão sistemática de estudos empíricos
}

\author{
Karine Costa Lima Pereira \\ Adriano Furtado Holanda
}

\section{RESUMO}

A revisão apresenta um panorama da literatura nacional que trata da vivência espiritual/ religiosa de graduandos no contexto da formação acadêmica do psicólogo. 0 objetivo foi delinear e analisar pesquisas empíricas sobre a relação entre estudantes, espiritualidade, religião e formação nos cursos de psicologia do país. Realizou-se uma busca nas bases de dados virtuais Biblioteca Virtual em Saúde,SciELO, PePSIC e no Banco de Teses e Dissertações da CAPES, sendo selecionados e analisados 11 estudos, no período de 2002 a 2017. Observou-se número reduzido de publicações, especialmente no formato de artigo. A maioria das pesquisas é oriunda de instituições confessionais e de Programas de Pósgraduação em Psicologia. Estudantes de psicologia tendem a apresentar índices menores de bem-estar espiritual quando comparados a outros estudantes universitários. Formandos de diferentes regiões do país mencionam sentir dificuldade e insegurança quando o assunto se apresenta na clínica. Questionam sobre a postura ética adequada; sentem medo de influenciar o paciente, de revelar a religião pessoal e não saber lidar com suas próprias crenças. Admitem falta de conhecimento e manejo teórico-clínico; e dificuldade ou impedimento de abordar tais questões com professores e supervisores de estágio.

Palavras-chave: estudantes de psicologia; formação do psicólogo; espiritualidade; religião.

\section{ABSTRACT}

This research presents an overview of Brazilian literature on the spiritual and religious experience of psychology students in the context of the psychologist's scientific and academic education. The purpose of this study was to outline and analyze empirical research that regard the relationship between students, spirituality, religion and education in psychology courses in Brazil. The databases used for this purpose were Virtual Library of Health, SciELO, PePSIC and the Bank of Thesis and Dissertations of CAPES. Ultimately, this resulted in the selection and analysis of 11 studies, stretching in the period from 2002 to 2017. This shows a reduced number of publications, especially in the article format. Most of the research comes from Higher Education Institutions with confessional ties. The analysis indicates that psychology students tend to have lower rates of spiritual well-being when compared to other university students. Undergraduates from different regions of the country mentioned experiencing difficulty and insecurity when the subject appears in the clinical practice. They question the proper ethical stance; they are afraid to influence the patient, to reveal their personal religion, and they fear not knowing how to deal with their own beliefs. They admit lack of knowledge and theoretical-clinical management, as well as the difficulty or hindrance of addressing such issues with teachers and internship supervisors.

Keywords: psychology students; psychologist training; spirituality; religion.

O crescente interesse pela religião e pela espiritualidade na contemporaneidade é notório no campo da psicologia e das ciências da saúde, especialmente na interface com a saúde mental (Moreira-Almeida, Koenig \& Lucchetti, 2014). Neste cenário, de crescimento de estudos voltados ao fenômeno religioso, se insere a Psicologia da Religião (PR), área que estuda os aspectos psicológicos da experiência espiritual/religiosa a partir de diferentes abordagens, conceitos e métodos (Belzen, 2009). É verdade que desde o início do século XX, a PR se

\section{Sobre os Autores}

K. C. L. P.

orcid.org/0000-0002-0500-4241 Universidade Federal do Paraná (UFPR) - Curitiba, PR.

karine_costalimapereira@yahoo .com.br

A. F. H.

orcid.org/0000-0002-7171-644X Universidade Federal do Paraná (UFPR) - Curitiba, PR. aholanda@yahoo.com

\section{Direitos Autorais}

Este é um artigo de acesso aberto e pode ser reproduzido livremente, distribuído,

transmitido ou modificado, por qualquer pessoa desde que usado sem fins comerciais. 0 trabalho é disponibilizado sob a licença Creative Commons CCBY-NC.

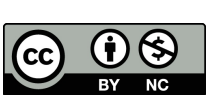




\section{-4: INTERACÃO EM LF PSICOLOGIA}

caracteriza como um campo fecundo na Europa e nos Estados Unidos, no entanto, seu ressurgimento no início do século XXI é inegável (Paloutzian, 2017), visto o que especialistas se dividem em analisar como retorno, persistência ou mesmo ameaça do religioso na cultura e sociedade pós-moderna - onde se lê, sua influência e repercussão na ciência e na pesquisa, na mídia e tecnologias modernas de comunicação, e na política (Oliveira \& Oliveira, 2012).

No contexto brasileiro, a PR tem-se estabelecido como uma área em expansão no meio acadêmico e científico. Levantamentos recentes indicam um crescimento gradual de pesquisas nesse campo desde a década de 1990, com incremento da pesquisa qualitativa e da interface da PR com outras áreas do conhecimento nos últimos 10 anos (Esperandio \& August, 2017; Paiva et al., 2009). No cenário acadêmico, seu desenvolvimento acontece principalmente nos Programas de Pós-graduação em Psicologia, Ciências da Religião e Teologia; no Grupo de Trabalho "Psicologia \& Religião" da Associação Nacional de Pesquisa e PósGraduação em Psicologia; e também nas Ciências Médicas e da Saúde (Esperandio \& Marques, 2015; Paiva, 2017b). No âmbito da formação superior em psicologia, todavia, a abordagem do tema parece assumir percursos diferentes. Menos de um quarto dos cursos de psicologia do país oferecem disciplinas voltadas especificamente para questões relacionadas à religião em seus currículos (Costa, Nogueira \& Freire, 2010; Piasson, 2017), mesmo diante do interesse latente ou expresso dos alunos, constituindo-se um tema distante das salas de aulas e contextos de supervisão (Ancona-Lopez, 2005; Paiva, 2017a).

Diante deste quadro, alguns pesquisadores ligados a programas de pós-graduação têm se dedicado a compreender e problematizar este cenário, dando visibilidade a um problema antagônico na formação humana, científica e profissional do psicólogo brasileiro (Ancona-Lopez, 2007, 2008, Freitas, 2007, 2012; Paiva, 2017a). Parte desse trabalho se concretiza na orientação de teses, dissertações e trabalhos de conclusão de curso que, em essência, problematizam tanto a relação da formação do psicólogo com o estudo da religião e espiritualidade quanto às percepções e vivências pessoais de espiritualidade/ religiosidade (E/R) de estudantes, professores, psicólogos, estagiários, líderes religiosos-psicólogos, etc. (Carneiro, 2008; Esteves, 2009; Machado, 2009; Oliveira, 2010; Piasson, 2017; Silva, 2010).

Com base nesse contexto, buscou-se neste artigo delinear e analisar a literatura que trata da vivência espiritual/religiosa de estudantes de psicologia (EP). 0 estudo teve como
Karine Costa Lima Pereira e Adriano Furtado Holanda

objetivo apresentar e analisar pesquisas empíricas nacionais sobre a relação entre EP, espiritualidade, religião e formação nos cursos de psicologia do país. Buscou-se apresentar um panorama desses estudos e seus principais resultados, tendo como foco de investigação a experiência de $E / R$ do graduando no contexto da formação científico-acadêmica do psicólogo.

\section{MÉTODO}

A revisão de literatura foi feita numa busca em bases de dados virtuais: Biblioteca Virtual em Saúde (BVS); Scientific Eletronic Library Online (SciELO); Periódicos Eletrônicos em Psicologia (PepSIC); e no Banco de Teses e Dissertações da CAPES, sendo a consulta realizada no primeiro trimestre de 2017. Como palavras-chave foram combinadas as expressões "estudantes", "acadêmicos", "graduandos" e "universitários" de psicologia; "formação do psicólogo" ou "formação em psicologia", com os descritores e/ou radicais espiritualidade, religião, religiosidade ou crenças religiosas.

Os critérios de inclusão foram a seleção de a) pesquisas empíricas cuja amostra incluísse estudantes universitários de psicologia e que considerassem como variáveis centrais a E/ $\mathrm{R}$ dos participantes e/ou a relação do tema religião com a graduação; e a b) qualidade e adequação metodológica do estudo. Critérios de exclusão: a) pesquisas realizadas com EP cujo foco fosse a validação de escalas ou a mensuração de variáveis específicas sem relação relevante com as variáveis crenças pessoais, formação e $E / R$; $b$ ) estudos teórico-críticos sobre formação em Psicologia; $c$ ) publicações oriundas de teses e dissertações, tais como relatos de pesquisa ou artigos, quando o trabalho principal estava disponibilizado online. A pré-seleção do material foi realizada a partir da leitura dos títulos e resumos e leitura flutuante dos artigos e dos tópicos metodologia e resultados, no caso das teses e dissertações.

Para análise dos dados foi realizada a leitura integral de todo o material selecionado para revisão, e os dados tabulados em categorias distintas de: a) identificação, b) método e c) caracterização da amostra. Uma segunda categorização foi desenvolvida a partir de uma análise qualitativa e uma sistematização descritiva dos resultados apresentados nos estudos. Os procedimentos de análise e de síntese em eixos temáticos consistiram na a) identificação dos principais resultados das pesquisas; b) descrição das crenças e perfil de E/R dos participantes; e c) apreensão de elementos e estruturas associados à experiência vivida dos EP no contexto da relação entre as crenças pessoais, formação profissional e ciência psicológica. 


\section{WIIINTERACÃO EM IT PSICOLOGIA}

\section{RESULTADOS}

A busca nas bases de dados localizou um total de 379 publicações, das quais 66 foram excluídas por duplicidade. A partir dos procedimentos de leitura e análise descritos anteriormente, das 313 publicações restantes, 54 foram préselecionadas e avaliadas. Com base nos critérios de inclusão e exclusão, foram encontradas 14 publicações, sendo todas estudos de natureza empírica. Dois artigos foram excluídos por se tratarem de publicações oriundas de uma tese e de uma dissertação já contempladas na seleção; e um terceiro, por não apresentar consistência metodológica. A partir deste

Tabela 1. Categorização das publicaçōes por identificação, tipo e método de pesquisa

\begin{tabular}{|c|c|c|c|c|c|}
\hline Publicação & Autores & Tipo & Area / PPGa & IES / UF & Metodologia \\
\hline $\begin{array}{c}\text { Crença religiosa e personalidade em } \\
\text { estudantes de psicologia. Um estudo por } \\
\text { meio do questionário Pratt e do Método de } \\
\text { Rorschach }\end{array}$ & $\begin{array}{l}\text { Freitas } \\
(2002)\end{array}$ & Tese & $\begin{array}{l}\text { Psicologia / } \\
\text { Psicologia }\end{array}$ & UnB / DF & Qualitativo \\
\hline $\begin{array}{l}\text { Bem-estar espiritual e transtornos } \\
\text { psiquiátricos menores em estudantes de } \\
\text { psicologia: estudo transversal }\end{array}$ & $\begin{array}{l}\text { Gastaudet al. } \\
\qquad(2006)\end{array}$ & Artigo & $\begin{array}{l}\text { Psicologia, } \\
\text { Medicina e } \\
\text { Teologia }\end{array}$ & $\begin{array}{l}\text { UCPEL / } \\
\quad \text { RS }\end{array}$ & Quantitativo \\
\hline $\begin{array}{c}\text { Qualidade de vida e bem-estar espiritual em } \\
\text { universitários de psicologia }\end{array}$ & $\begin{array}{l}\text { Costa et al. } \\
\qquad(2008)\end{array}$ & Artigo & Psicologia & PUC-RS & Quantitativo \\
\hline $\begin{array}{l}\text { Crenças religiosas entre estudantes de } \\
\text { graduação em psicologia }\end{array}$ & $\begin{array}{l}\text { Ferreti } \\
(2010)\end{array}$ & Dissertação & $\begin{array}{l}\text { Psicologia / } \\
\text { Educação em } \\
\text { Ciências e Saúde }\end{array}$ & UFRJ / RJ & Misto \\
\hline $\begin{array}{c}\text { Espiritualidade na clínica psicológica: um } \\
\text { olhar sobre a formação acadêmica no Rio } \\
\text { Grande do Sul }\end{array}$ & $\begin{array}{l}\text { Cavalheiro } \\
\text { (2010) }\end{array}$ & Dissertação & $\begin{array}{l}\text { Psicologia / } \\
\text { Psicologia }\end{array}$ & $\begin{array}{l}\text { UNISINOS } \\
\quad / \text { RS }\end{array}$ & Misto \\
\hline $\begin{array}{c}\text { Crenças religiosas e conhecimento } \\
\text { psicológico na perspectiva do aluno do } \\
\text { curso de psicologia }\end{array}$ & Pinho (2012) & Dissertação & $\begin{array}{l}\text { Psicologia / } \\
\text { Psicologia }\end{array}$ & PUC-SP & Qualitativo \\
\hline $\begin{array}{l}\text { A religiosidade e a espiritualidade dos } \\
\text { alunos no curso de formação dos } \\
\text { psicólogos }\end{array}$ & $\begin{array}{l}\text { Gandelman } \\
\text { (2013) }\end{array}$ & Dissertação & $\begin{array}{l}\text { Psicologia / } \\
\text { Psicologia }\end{array}$ & PUC-SP & Qualitativo \\
\hline $\begin{array}{l}\text { Religiosidade e bem-estar psicológico de } \\
\text { acadêmicos de psicologia }\end{array}$ & $\begin{array}{l}\text { Vieira et al. } \\
\qquad(2013)\end{array}$ & Artigo & $\begin{array}{l}\text { Psicologia, } \\
\text { Teologia e } \\
\text { Antropologia }\end{array}$ & PUC-GO & Quantitativo \\
\hline $\begin{array}{c}\text { Psicologia e espiritualidade - grupo } \\
\text { temático com alunos adventistas de } \\
\text { graduação em psicologia }\end{array}$ & Souza (2014) & Dissertação & $\begin{array}{l}\text { Psicologia / } \\
\text { Psicologia }\end{array}$ & PUC-SP & Qualitativo \\
\hline $\begin{array}{l}\text { Espiritualidades e bem-estar espiritual no } \\
\text { processo formativo de estudantes de } \\
\text { psicologia do Recife-PE à luz da abordagem } \\
\text { Integral/Transpessoal }\end{array}$ & Silva (2016) & Dissertação & $\begin{array}{l}\text { Psicologia / } \\
\text { Educação }\end{array}$ & UFPE / PE & Misto \\
\hline $\begin{array}{l}\text { Religiosidade, espiritualidade e psicoterapia } \\
\text { na formação acadêmica do psicólogo }\end{array}$ & $\begin{array}{l}\text { Nascimento } \\
\text { (2017) }\end{array}$ & Tese & $\begin{array}{c}\text { Psicologia / } \\
\text { Psicologia }\end{array}$ & $\begin{array}{l}\text { UNICAP / } \\
\text { PE }\end{array}$ & Qualitativo \\
\hline
\end{tabular}

procedimento foram selecionados para esta revisão o total de 11 estudos, dos quais seis são dissertações de mestrado, duas teses de doutorado e três artigos, com período de publicação e/ou realização de 2002 a 2017.

Quanto à origem institucional, sete pesquisas são oriundas de Instituições de Ensino Superior (IES) confessionais e três de IES públicas federais. Dentre as públicas, duas foram realizados em Programas de Pósgraduação na área da Educação. Três pesquisas foram desenvolvidas na Pontifícia Universidade Católica de São Paulo, sendo todas dissertações de mestrado orientadas pela professora Marília Ancona-Lopez (Tabela 1): 


\section{N"INTERACÃO EM ETSPICOLOGIA}

Quanto aos procedimentos metodológicos (Tabela 2), cinco são qualitativos, quatro quantitativos e dois mistos, com coleta de dados realizada a partir de questionários, escalas, entrevistas e grupos focais. Quatro pesquisas

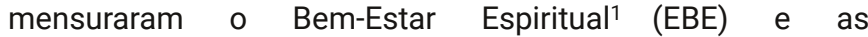

subdimensões Bem-Estar Existencial (BEE) e Bem-Estar Religioso (BER) utilizando a escala de Paloutzian e Elisson (1982). Dois estudos avaliaram a qualidade de vida com base na escala da OMS, a World Health Organization Quality of Life (WHOQOL).

Tabela 2. Caracterização metodológica das publicaçōes

\begin{tabular}{|c|c|c|c|c|}
\hline Autores & Objetivos & Procedimentos de coleta & Análise dos dados & Referencial teórico \\
\hline $\begin{array}{l}\text { Freitas } \\
(2002)\end{array}$ & $\begin{array}{l}\text { Investigar as relações entre } \\
\text { crenças religiosas e } \\
\text { características de } \\
\text { personalidade }\end{array}$ & $\begin{array}{l}\text { - Entrevista individual } \\
\text { - Grupo focal } \\
\text { - Questionário Pratt sobre } \\
\text { Crença Religiosa adaptado } \\
\text { - Método de Rorschach }\end{array}$ & $\begin{array}{l}\text { - Análise } \\
\text { Fenomenológica } \\
\text { - Análise das } \\
\text { Modalidades de } \\
\text { Crença por James } \\
\text { Pratt }\end{array}$ & $\begin{array}{l}\text { Fenomenologia de } \\
\text { Husserl e Merleau-Ponty }\end{array}$ \\
\hline $\begin{array}{l}\text { Gastaudet } \\
\text { al. (2006) }\end{array}$ & $\begin{array}{l}\text { Investigar se a graduação } \\
\text { pode estar associada a } \\
\text { baixos índices de EBE e a } \\
\text { relação entre saúde mental } \\
\text { e religiosidade }\end{array}$ & $\begin{array}{l}\text { - EBE } \\
\text { - Self-Reporting } \\
\text { Questionnaire }\end{array}$ & $\begin{array}{l}\text { - Teste qui- } \\
\text { quadrado } \\
\text { - Regressão } \\
\text { logística } \\
\text { - Razão de } \\
\text { chances }\end{array}$ & Não se aplica \\
\hline $\begin{array}{l}\text { Costa et al. } \\
(2008)\end{array}$ & $\begin{array}{l}\text { Avaliar qualidade de vida e } \\
\text { EBE e a relação desses } \\
\text { aspectos com a formação }\end{array}$ & $\begin{array}{l}\text { - EBE } \\
\text { - WHOQOL }\end{array}$ & $\begin{array}{l}\text { - Correlação de } \\
\text { Spearman } \\
\text { - Teste de Mann- } \\
\text { Whitney }\end{array}$ & Não se aplica \\
\hline $\begin{array}{l}\text { Ferreti } \\
(2010)\end{array}$ & $\begin{array}{l}\text { Investigar a presença de } \\
\text { crença religiosa e a } \\
\text { dinâmica de mudanças ao } \\
\text { longo da formação em IES } \\
\text { pública e privada }\end{array}$ & $\begin{array}{l}\text { - Questionário } \\
\text { semiestruturado }\end{array}$ & $\begin{array}{l}\text { - Estatística } \\
\text { descritiva } \\
\text { - Teste qui- } \\
\text { quadrado e de } \\
\text { correlação Phi } \\
\text { - Discurso do } \\
\text { Sujeito Coletivo de } \\
\text { Lefèvre e Lefèvre }\end{array}$ & $\begin{array}{l}\text { Conceito de } \\
\text { Representação Social de } \\
\text { Serge Moscovici }\end{array}$ \\
\hline $\begin{array}{l}\text { Cavalheiro } \\
(2010)\end{array}$ & $\begin{array}{l}\text { Comparar calouros e } \\
\text { formandos com base na } \\
\text { EBE e na dimensão de E/R e } \\
\text { crenças pessoais. } \\
\text { Compreender como a } \\
\text { espiritualidade foi abordada } \\
\text { na formação }\end{array}$ & $\begin{array}{l}\text { - EBE } \\
\text { - WHOQOL } \\
\text { - Questionário sobre Valores } \\
\text { e Aspectos Espirituais e } \\
\text { Religiosos } \\
\text { - Grupo focal }\end{array}$ & $\begin{array}{l}\text { - Estatística } \\
\text { descritiva } \\
\text { - Testes } \\
\text { paramétricos e } \\
\text { não paramétricos } \\
\text { - Análise de } \\
\text { Conteúdo (Minayo) }\end{array}$ & $\begin{array}{l}\text { Psicologia Transpessoal } \\
\text { e correntes } \\
\text { existencialistas, } \\
\text { humanistas }\end{array}$ \\
\hline $\begin{array}{l}\text { Pinho } \\
(2012)\end{array}$ & $\begin{array}{l}\text { Saber como articulam } \\
\text { crenças religiosas e visão } \\
\text { de homem e de mundo com } \\
\text { os conhecimentos } \\
\text { adquiridos no curso }\end{array}$ & - Entrevista semidiretiva & $\begin{array}{l}\text { - Análise de } \\
\text { Conteúdo }\end{array}$ & Não usa/menciona \\
\hline
\end{tabular}

${ }^{1}$ A EBE, originalmente Spiritual Well-Being Scale (SWBS), é composta por 20 itens e se propõem a medir um sentido psicológico do bem-estar espiritual a partir de uma dimensão vertical ou religiosa e uma dimensão horizontal ou existencial. Os escores gerais da EBE assumem os intervalos de 20 a 40,41 a 99 e 100 a 120, para baixo, moderado e alto, respectivamente. Nas subescalas, os intervalos são de 10 a 20,21 a 49 e 50 a 60 pontos. Nos estudos analisados, os resultados foram admitidos como bem-estar espiritual positivo para escores altos e negativo para escores moderado e baixo. 
(continuação da Tabela 2)

\begin{tabular}{|c|c|c|c|c|}
\hline $\begin{array}{l}\text { Gandelman } \\
\text { (2013) }\end{array}$ & $\begin{array}{l}\text { Compreender a E/R de } \\
\text { formandos que valorizam a } \\
\text { dimensão } \\
\text { espiritual/religiosa }\end{array}$ & - Entrevista semidirigida & $\begin{array}{l}\text { - Análise de } \\
\text { Conteúdo }\end{array}$ & Não usa/menciona \\
\hline $\begin{array}{l}\text { Vieira et al. } \\
\text { (2013) }\end{array}$ & $\begin{array}{l}\text { Avaliar atitude religiosa, } \\
\text { bem-estar psicológico e } \\
\text { físico e interação entre } \\
\text { religiosidade e formação }\end{array}$ & $\begin{array}{l}\text { - Questionários de Avaliação } \\
\text { de Atitude Religiosa e de } \\
\text { Interação Religiosidade- } \\
\text { Formação em Psicologia } \\
\text { - Questionário de Bem-estar } \\
\text { Psicológico e Físico }\end{array}$ & $\begin{array}{l}\text { - Estatística } \\
\text { descritiva } \\
\text { - Correlação de } \\
\text { Person }\end{array}$ & Não se aplica \\
\hline $\begin{array}{l}\text { Souza } \\
(2014)\end{array}$ & $\begin{array}{l}\text { Compreender como } \\
\text { relacionam a psicologia e } \\
\text { espiritualidade }\end{array}$ & $\begin{array}{l}\text { - Grupo temático } \\
\text { - Relato escrito }\end{array}$ & $\begin{array}{l}\text { - Análise } \\
\text { qualitativa }\end{array}$ & Kenneth Pargament \\
\hline Silva (2016) & $\begin{array}{l}\text { Investigar EBE e concepção } \\
\text { de espiritualidade nos } \\
\text { processos de formação. } \\
\text { Compreender como } \\
\text { abordam a espiritualidade e } \\
\text { suas contribuições na } \\
\text { formação humana }\end{array}$ & $\begin{array}{l}\text { - EBE } \\
\text { - Questionário estruturado } \\
\text { - Entrevista Semiestruturada }\end{array}$ & $\begin{array}{l}\text { - Teste Mann- } \\
\text { Whitney U } \\
\text { - Análise de } \\
\text { Conteúdo (Minayo) }\end{array}$ & $\begin{array}{l}\text { Abordagem } \\
\text { Integral/Transpessoal } \\
\text { de Ken Wilber }\end{array}$ \\
\hline $\begin{array}{l}\text { Nascimento } \\
(2017)\end{array}$ & $\begin{array}{l}\text { Compreender e inter- } \\
\text { relacionar religião e E/R na } \\
\text { formação de } \\
\text { psicoterapeutas }\end{array}$ & $\begin{array}{l}\text { - Análise documental de } \\
\text { matrizes curriculares } \\
\text { - Entrevista semiestruturada }\end{array}$ & $\begin{array}{l}\text { - Método } \\
\text { Processamento } \\
\text { Simbólico- } \\
\text { arquetípico }\end{array}$ & Psicologia Analítica \\
\hline
\end{tabular}

Nota:(a) Resultados não abordados nesta revisão.

Os estudos compreenderam uma amostra de 2.245 EP, de seis diferentes Estados, mais Distrito Federal $(\mathrm{N}=7)$. Há predomínio do sexo feminino, de jovens, representando aproximadamente 35 cursos diferentes de psicologia. Nos estudos de base qualitativa, cinco coletaram dados com EP em fase final de curso. Dos quantitativos, a maioria é de recorte transversal $(\mathrm{N}=4)$ e dois compararam calouros e formandos. A Tabela 3 agrupa dados de caracterização dos estudantes e IES participantes que compõem a amostra analisada.

Para apresentação dos principais resultados, privilegiouse a descrição individualizada dos estudos por ordem cronológica e tipo de metodologia. Na sequência, uma análise qualitativa dos dados é apresentada de forma sistematizada em eixos temáticos.

\section{ESTUDOS QUANTITATIVOS}

Gastaud et al. (2006) comparou seus achados com os resultados encontrados por Volcan, Sousa, Mari e Horta (2003) em pesquisa equivalente realizada com estudantes de medicina e direito da mesma instituição. Observou-se preeminência de escores baixos e moderados na EBE e na BEE em EP quando comparados a alunos de medicina e direito. Quanto à prevalência de transtornos psiquiátricos menores (TPM), não foram encontradas diferenças significativas, porém, os resultados apontam para uma relação inversa entre os níveis de bem-estar espiritual e os escores de TPM, sugerindo que EP com esses transtornos apresentam maior probabilidade de obterem baixas pontuações na escala.

$\mathrm{Na}$ pesquisa realizada por Costa et al. (2008), cerca de $36 \%$ dos participantes já se haviam deparado com questões relacionadas à espiritualidade em alguma prática do curso, como estágios e atendimentos, e 77,9\% afirmaram ter interesse em discutir o tema durante a formação. Os resultados indicaram escores altos de qualidade de vida e moderados na EBE $(M=87,95)$. Na subescala BEE $(M=46,51)$, a média dos participantes aparece mais elevada que na BER $(M=41,73)$, sugerindo que os estudantes relacionam o bemestar espiritual mais a uma sensação de encontro de algo significativo na vida do que a uma referência a Deus. Os 


\section{W'INTERACÃO EM ET. PSICOLOGIA}

Tabela 3. Caracterização da amostra e IES participantes

\begin{tabular}{|c|c|c|c|c|}
\hline \multirow{2}{*}{ Autores } & \multicolumn{2}{|c|}{ Participantes } & \multicolumn{2}{|c|}{ Instituição de Ensino Superior } \\
\hline & Dados sociodemográficos & Perfil religioso & $\begin{array}{l}\text { Categoria } \\
\text { administrativa }\end{array}$ & UF \\
\hline Freitas (2002) & $\begin{array}{l}\text { Amostra }(\mathrm{N}=52) \\
\text { Sexo: } \mathrm{F}(\mathrm{N}=35) \text { / } \mathrm{M}(\mathrm{N}=17) \\
\text { Faixa etária } 18 \text { a } 25 \\
\text { Primeiro ao sexto período de } \\
\text { curso }\end{array}$ & $\begin{array}{l}\text { Crença em Deus e adesão a } \\
\text { religião }(\mathrm{N}=35) \\
\text { Crença em Deus, sem adesão a } \\
\text { religião }(\mathrm{N}=14) \\
\text { Conflito e ambivalência }(\mathrm{N}=6) \\
\text { Ceticismo }(\mathrm{N}=2) \\
\text { Ateísmo }(\mathrm{N}=1)\end{array}$ & $\begin{array}{l}\text { Confessional Católica } \\
(\mathrm{N}=1)\end{array}$ & $\mathrm{DF}$ \\
\hline $\begin{array}{l}\text { Gastaud et al. } \\
(2006)\end{array}$ & $\begin{array}{l}\text { Amostra }(N=351) \\
\text { Sexo: } \mathrm{F}(\mathrm{N}=299) \text { / } \mathrm{M}(\mathrm{N}=37) \\
\text { Faixa etária } 17 \text { a } 64 \\
\text { Totalidade dos EP do curso }\end{array}$ & $\begin{array}{l}\text { Não apresenta dados sobre prática } \\
\text { e/ou pertencimento religioso }\end{array}$ & $\begin{array}{l}\text { Confessional Católica } \\
(\mathrm{N}=1)\end{array}$ & RS \\
\hline $\begin{array}{l}\text { Costa et al. } \\
(2008)\end{array}$ & $\begin{array}{l}\text { Amostra }(N=136) \\
\text { Sexo: } F(N=115) / M(N=21) \\
\text { Idade média } 22,57 \\
\text { Primeiro ao décimo período } \\
\text { de curso }\end{array}$ & $\begin{array}{l}\text { Possuem religião (86\%) / católicos } \\
(47,2 \%) \\
\text { Interesse na espiritualidade }(83,8 \%) \\
\text { Conversam com amigos/colegas } \\
(63 \%) \\
\text { Não frequentam }(70,4 \%)\end{array}$ & $\begin{array}{l}\text { Confessional Católica } \\
(\mathrm{N}=1)\end{array}$ & RS \\
\hline Ferreti (2010) & $\begin{array}{l}\text { Amostra }(\mathrm{N}=256) \\
\text { IES pública }(\mathrm{N}=127) \\
\text { IES privada }(\mathrm{N}=129) \\
\text { Sexo: não informa } \\
\text { Faixa etária predomínio } 17 \text { a } \\
25 \\
\text { Fases início, meio e final de } \\
\text { curso }\end{array}$ & $\begin{array}{l}\text { Acreditam em Deus ( } 81 \%) \\
\text { Católicos, evangélicos, espíritas, } \\
\text { outros }(64,4 \%) \\
\text { Frequentam atividades semanais } \\
(42,64 \%) \\
\text { Raramente frequentam }(44,8 \%)\end{array}$ & $\begin{array}{l}\text { Pública }(\mathrm{N}=1) \\
\text { Privada }(\mathrm{N}=1)^{\mathrm{a}}\end{array}$ & RJ \\
\hline $\begin{array}{l}\text { Cavalheiro } \\
(2010)\end{array}$ & $\begin{array}{l}\text { Amostra }(\mathrm{N}=1064) \\
\text { Calouros }(\mathrm{N}=672) \\
\text { Formandos }(\mathrm{N}=392) \\
\text { Sexo: } \mathrm{F}(85,7 \%) / \mathrm{M}(13,6 \%) \\
\text { Idade média } 23,44 \text { (calouros) } \\
\text { / } \\
28,1 \text { (formandos) } \\
\text { Grupo focal Confessional } \\
(\mathrm{N}=9) \text { Pública }(\mathrm{N}=10)\end{array}$ & $\begin{array}{l}\text { Não apresenta dados sobre prática } \\
\text { e/ou pertencimento religioso }\end{array}$ & $\begin{array}{l}\text { IES com formandos } \\
\text { em } 2009(\mathrm{~N}=25) \\
\text { Grupo focal: } \\
\text { Confessional Luterana } \\
(\mathrm{N}=1) \\
\text { Pública Federal }(\mathrm{N}=1)\end{array}$ & RS \\
\hline Pinho (2012) & $\begin{array}{l}\text { Amostra }(\mathrm{N}=5) \\
\text { Faixa etária } 21 \text { a } 61 \\
\text { Sexo feminino } \\
\text { Oitavo e décimo período de } \\
\text { curso }\end{array}$ & $\begin{array}{l}\text { Católica }(N=1) \\
\text { Evangélica }(N=1) \\
\text { Umbandista }(N=1) \\
\text { Sem religião }(N=2)\end{array}$ & $(\mathrm{N}=1)^{\mathrm{a}}$ & SP \\
\hline $\begin{array}{l}\text { Gandelman } \\
\text { (2013) }\end{array}$ & $\begin{array}{l}\text { Amostra }(\mathrm{N}=2) \\
\text { Sexo } \mathrm{F}, 25 \text { anos / } \mathrm{M}, 23 \text { anos } \\
\text { Último ano de curso }\end{array}$ & $\begin{array}{l}\text { Evangélica }(N=1) \\
\text { Sem religião }(N=1)\end{array}$ & $(N=1)^{a}$ & $\begin{array}{l}\text { Não } \\
\text { informa }\end{array}$ \\
\hline $\begin{array}{l}\text { Vieira et al. } \\
(2013)\end{array}$ & $\begin{array}{l}\text { Amostra }(\mathrm{N}=168) \\
\text { Sexo: } \mathrm{F}(82,1 \%) / \mathrm{M}(17,9 \%) \\
\text { Idade média } 22,88 \\
\text { Fases início, meio e final de } \\
\text { curso }\end{array}$ & $\begin{array}{l}\text { Católicos }(47,2 \%) \\
\text { Evangélicos }(21,4 \%) \\
\text { Espíritas }(15,1 \%) \\
\text { Sem Religião }(8,8 \%)\end{array}$ & $\begin{array}{l}\text { Privada Filantrópica } \\
(\mathrm{N}=1)^{\mathrm{a}}\end{array}$ & GO \\
\hline
\end{tabular}




\section{H NTERAC̄̈OEM ES PSICOLOGIA}

(continuação da Tabela 3)

Souza (2014)

Amostra $(\mathrm{N}=6)$

Faixa etária 22 a 32

Último período de curso
Confessional

Adventista $(\mathrm{N}=1)$

Pública Federal $(\mathrm{N}=1)$ Confessional Católica $(\mathrm{N}=1)$

Não apresenta dados sobre prática e/ou pertencimento religioso
PE

IES pública $(\mathrm{N}=94)$

IES confessional $(\mathrm{N}=108)$

Sexo: $F(N=155) / M$

$(\mathrm{N}=42)$

Faixa etária: não informa

Calouros e formandos

Nascimento

(2017)
Amostra $(\mathrm{N}=6)$

Estudante $(\mathrm{N}=3)$

Professor-supervisor

$(\mathrm{N}=3)$

Sexo estudantes: $\mathrm{F}(\mathrm{N}=2)$

/ $\mathrm{M}(\mathrm{N}=1)$

Faixa etária 23 a 32

(estudantes)

Último ano de curso

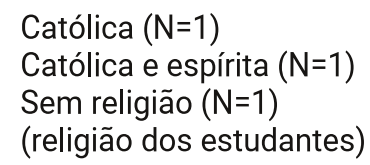

Nota:(a) Categoria administrativa não informada pelos autores.

dados também apontaram correlações positivas entre o domínio psicológico da qualidade de vida com a BER e BEE e, de igual modo, correlação positiva da BEE com todos os domínios mensurados pelo instrumento (físico, psicológico, relações sociais, ambiente e saúde geral).

Cavalheiro (2010) encontrou escores moderados na EBE $(M=90,04)$, BEE $(M=46)$ e BER $(M=44)$, com diferenças significativas entre calouros e formandos (EBE e BER), tendo os primeiros, média superior em todas as dimensões. Sobre valores e aspectos espirituais religiosos, o estudo encontrou diferenças significativas entre os grupos: $93,1 \%$ dos calouros e $87,2 \%$ dos formandos acreditam em Deus e/ou Força Superior; $17,7 \%$ dos calouros e $27,8 \%$ dos formandos referemespiritualidade como aspecto de menor prioridade em suas vidas; $73,2 \%$ dos calouros e $56,6 \%$ dos formandos consideram importante ou extremamente importante a espiritualidade para lidar com situações da vida pessoal. Também foram encontradas diferenças significativas nas questões condicionadas à prática profissional: $69,3 \%$ dos formandos e $46,2 \%$ dos calouros consideram pouco ou nada importante a dimensão espiritual para prática clínica; e 85,9\% dos calouros e $74 \%$ dos formandos consideram que a espiritualidade influencia negativamente ou muito negativamente a saúde. 0 estudo também indicou diferenças significativas entre as linhas teóricas dos formandos e os índices na $E B E$, sendo o grupo com menor média o dos $E P$ que se identificam com a Psicanálise $(M=85,18)$.

Ferreti (2010) identificou que ambos os grupos, EP das IES públicas e privadas, apresentam alto perfil de adesão religiosa, que se mantém durante o curso. Contudo, as frequências sugerem que os EP da IES pública são menos adeptos à religião institucionalizada (34,7\% acreditam em Deus, mas não tem religião) do que os da privada $(23,2 \%)$, apresentando também número muito superior de ateus (10,2\% na pública para $3,1 \%)$.

Vieira, Zanini e Amorim (2013) avaliaram a percepção dos EP sobre a atitude dos professores frente às crenças religiosas e a experiência de conflitos. Nos resultados, EP que se afirmaram como muito religiosos apresentaram índices maiores de atitude religiosa e maior bem-estar físico e psicológico. EP que apresentaram índices mais elevados de atitude religiosa também indicaram pensar com maior frequência nas suas crenças durante as aulas. A pesquisa encontrou correlação positiva entre atitude religiosa e vivência de conflito no estudo de algumas abordagens psicológicas - dentre os que discriminaram alguma abordagem, $61 \%$ indicaram a Psicanálise como a abordagem em maior conflito com suas crenças religiosas, 14,8\% o Behaviorismo e 9,3\% a Gestalt. Sobre a percepção de que os professores respeitam a religiosidade dos alunos, os dados indicaram correlação negativa com as variáveis período e atitude religiosa, sugerindo que EP mais avançados no curso e/ou mais religiosos tendem a perceber com mais frequência atitudes dos professores como desrespeitosas em relação às suas crenças. A vivência de conflito com as abordagens igualmente indica correlação positiva com a percepção sobre o comportamento dos professores e a percepção de que a formação em psicologia pode provocar os EP a abandonarem 
suas crenças religiosas. Silva (2016) igualmente identificou, entre calouros e formandos das IES pública e confessional, escores moderados na $\operatorname{EBE}(M=4,63$ para variação de 1 a 6$)$, porém sem diferenças entre os grupos.

\section{ESTUDOS OUALITATIVOS}

Em Freitas (2002), as respostas ao Questionário Pratt indicaram um predomínio da modalidade crença emocional, seguida das primitiva e intelectual. Uma sistematização da análise revelou que a maioria dos colaboradores entende a religião como a crença na existência de um Ser ou Força Superior. Consideram a religião como uma experiência emocional; descrevem acreditar em Deus por já terem experimentado sua presença; ou com base em argumentos. Aceitam a Bíblia como autoridade em questões religiosas; afirmam rezar, orar ou fazer preces; acreditar que Deus as ouve; e acreditar na vida após a morte. Os resultados revelaram elevada mobilização afetiva em falar sobre o tema durante a formação, dada a percepção de que há um silenciamento sobre o assunto na Universidade e no curso. Questionam acerca da tendência de patologização da experiência religiosa, comum em várias teorias psicológicas. Tanto EP crentes quanto ateus ou céticos apresentaram dificuldade e desconforto em expor sobre suas crenças no ambiente acadêmico e entre seus pares. 0 impacto dos conteúdos estudados no curso sobre a experiência religiosa dos EP se destaca no conflito intrapessoal em relação às crenças ou não crenças em Deus ou na dimensão transcendente; no conflito interpessoal com colegas ou professores; e nas preocupações de cunho ético em relação à própria postura e prática profissional.

Com base na diferença significativa encontrada entre as IES nos escores da EBE, Cavalheiro (2010) realizou grupos focais com os formandos do curso que obtiveram maior $(M=98,73)$ e menor média $(M=78,73)$. Ambos estão localizados na capital, sendo a primeira uma IES confessional luterana e a segunda uma IES pública federal. O perfil dos participantes difere em relação à faixa etária, experiências pessoais e profissionais e no interesse em estudos sobre espiritualidade. Os EP com índices maiores na EBE assumem alterações positivas no desenvolvimento da espiritualidade pessoal durante o curso e identificam uma indissociabilidade entre o amadurecimento pessoal, profissional e espiritual; relataram possuir interesse pessoal e profissional sobre o tema da espiritualidade e buscam conhecer mais através de leituras e participação em eventos científicos. Revelam uma concepção de humano que inclui a espiritualidade, seja através da religião ou não; analisam a relação espiritualidadesaúde como algo que pode se apresentar tanto de forma positiva quanto negativa. Consideram que o tema não foi abordado no curso de forma satisfatória e não se sentem preparados profissionalmente para lidar com o assunto, mas apontam disciplinas específicas da grade, quando estudaram religião, como facilitadoras e fomentadoras do interesse pelo tema. Consideram o estudo da religião e espiritualidade como muito relevante para qualificação e ética profissional frente a uma escuta inclusiva.

Os EP com índices menores observam que a espiritualidade pessoal regrediu durante a formação e que a identificação com as linhas teóricas e os conteúdos vistos no curso pode preencher o espaço antes ocupado pela espiritualidade em suas vidas; ainda sim, relatam serem espiritualizados, possuírem crenças pessoais e vivenciarem experiências religiosas, místicas e mediúnicas. A maioria concebe uma visão de ser humano biopsicossocial, que explica a espiritualidade por essa via, e como tema que não compete ao psicólogo, pois transcende o estudo científico. Sobre a relação espiritualidade-saúde mostram-se reticentes, pautando-se em exemplos negativos como relatos de casos em que dogmas e fanatismo religioso se sobrepõem ao tratamento indicado; revelam preconceito, evitação e pouco conhecimento sobre a literatura científica sobre o tema. Relatam que o tema não foi abordado durante o curso e percebem o silêncio como um indicativo de como o assunto deve ser tratado. Sentiram-se silenciados logo no inicio do curso e identificam que o tema pode ser estudado até mesmo na própria IES, porém em outros contextos. Identificam que as abordagens estudadas no curso de forma geral são todas oposicionistas ao pensamento ligado à religiosidade e identificam as linhas teóricas e a própria ciência como um tipo de crença. Embora relatem experiências no estágio profissional e de vivência religiosa/ espiritual na vida pessoal, a maioria assume que o assunto não deve aparecer na clínica, que a espiritualidade não deve compor as concepções do psicólogo e que este deve até mesmo se opor, dado que costumam analisar esse tipo de experiência como sintoma ou muleta.

Ferreti (2010) investigou a possibilidade de influência da graduação na representação de Deus dos EP e observou que o discurso coletivo "Deus é protetor", que exemplifica descrições de Deus como um Ser, Força, Energia ou Entidade Superior que protege e interfere em tudo e na vida das pessoas, como central na elaboração da maioria $(61,7 \%)$ dos EP de ambas as instituições. O discurso "Deus é força e energia" e "Deus é indefinível" aparece mais associado à descrição dos crentes sem religião, especialmente no caso de EP de fim de curso da instituição pública. A representação de Deus como projeção de uma necessidade humana também aparece, contudo de pouca representatividade em ambos os grupos (8\%). 
No estudo de Pinho (2012), todas as colaboradoras relataram ter vivenciado experiências significativas durante o curso que influenciaram suas crenças e/ou a relação institucional com suas religiões de origem. As experiências, que foram do conflito à ressignificação, exemplificam-se no caso da colaboradora de 44 anos que deixou de ser freira católica após o terceiro ano da graduação; da umbandista, de 28 anos, que precisou trancar o curso devido ao grande conflito com suas crenças; e da evangélica, de 21 anos, que em sua formação fez o movimento de selecionar e assimilar os elementos que convergem com sua fé. As falas também expõem casos de abandono e ruptura com as crenças religiosas e uma consequente mudança de referencial: do religioso para o psicanalítico. Em relação à prática profissional relatam dificuldade e insegurança com o fazer psicológico quando o assunto é abordado pelos clientes, experiência que todas já haviam tido em seus atendimentos. Os embaraços quanto aos temas aparecem na menção recorrente de que os professores veiculam visões negativas ou mencionam (ensinam) que o assunto não deve ser tratado na clínica, posições que se revelam como fonte de dúvidas e que não deixamespaço para diálogo.

Gandelman (2013) identificou que os colaboradores refletem sobre sua formação científica e profissional com base em suas experiências de vida, valores, crenças e sentimentos, sendo tais aportes o que os incentiva a buscar sentido e respostas para sua prática como futuros psicólogos. Nessa busca está implícita a questão da E/R e as dificuldades em relacionar experiências e histórias de vida aos conhecimentos aprendidos durante o curso. 0 movimento realizado por cada um dos colaboradores, no entanto, é curiosamente diferente. 0 jovem que não declara pertencimento religioso acredita que a religião e a espiritualidade são aspectos inerentes ao humano, logo, merecem acolhimento e atenção ativa por parte do psicólogo. Sua visão de homem integral e a importância desta noção para sua prática redirecionou sua orientação teórica da Psicanálise para Fenomenologia, visto que ponderou, nesta última, haver recursos para acolher as crenças dos pacientes. Diante dessas experiências no contexto de sua prática no estágio, afirma que foi sua espiritualidade que o ajudou a pensar isso como psicólogo. A estudante de religião evangélica, de forma oposta, acredita que há uma dicotomia entre ciência e religião, o que a direcionou a uma busca por deixar suas crenças religiosas de fora e, assim, poder se abrir ao conhecimento científico. Desejando ser mais assertiva em sua prática, escolheu a Psicologia Cognitiva Comportamental. Motivou este movimento o medo de que suas crenças a destituíssem de seu valor profissional, assim como o exercício da neutralidade. 0 estudo mostrou que os EP se preocupam com a relação entre suas crenças pessoais e as de seus pacientes, tema que se mostrou presente já nos primeiros atendimentos. Para eles, a interferência é direta e inevitável no nível profissional.

Nos resultados de Souza (2014), as diferentes experiências e matizes de opiniões se destacaram, ainda que todas as colaboradoras pertencessem à mesma denominação religiosa. A espiritualidade é conceituada como uma experiência íntima e pessoal e uma vivência relacionada à figura de Deus ou ao indivíduo. A religiosidade é descrita como o aspecto mais organizado e socialmente estruturado dessa dimensão humana. No contexto da vivência pessoal, a espiritualidade aparece como experiência de contemplação do sagrado; de autonomia na opção religiosa e na influência dos relacionamentos familiares e sociais. Psicologia e espiritualidade são compreendidas como áreas que tem objetivos comuns e que por isso podem atuar paralelamente. $\mathrm{Na}$ experiência pessoal como estudantes da ciência psicológica descrevem a psicologia como aquela que colabora para um desenvolvimento mais satisfatório da espiritualidade, como elemento de crise, questionamento e reorganização espiritual. Em relação à formação, a temática da espiritualidade indica ser trabalhada pela IES como um todo; entretanto, no que se refere à relação com a psicologia, as colaboradoras sentem uma lacuna. A figura do professorsupervisor aparece como influenciadora, tanto de forma positiva quanto negativa, considerando a abertura ou não para discutir o tema com os alunos. Sentem falta de uma abordagem que auxilie a trabalhar com a espiritualidade do paciente. Sobre a relação entre espiritualidade do psicólogo e espiritualidade do paciente, a maioria considera que o trabalho do psicólogo deve ser independente, e que se deve conhecer a religião do paciente. Uma das colaboradoras, porém, considera que pode ser positivo para o paciente quando ambos compartilham os mesmos valores religiosos.

Os relatos indicam dificuldade em compreender a espiritualidade amplamente e de como abordá-la na clínica, bem como conflito e angústia entre o que devem fazer como psicólogas quando seus valores pessoais divergem do processo terapêutico do cliente. Tais dificuldades e posturas incluem o medo de influenciar o cliente; a tendência a esquivar-se do assunto no atendimento; a opção por uma neutralidade que se transforma em fuga; e a dificuldade com a discordância ou com a identificação de questões relacionadas ao sagrado.

A partir da abordagem Transpessoal, Silva (2016) identificou como principais significados atribuídos à espiritualidade as concepções de Espiritualidade como Bemestar Pessoal; Resiliência; e Relações Consigo e Suas Crenças, tendo a última maior representatividade (55\%) entre calouros e formandos. Tal concepção aparece relacionada à 


\section{-4: INTERACÃO EM LF PSICOLOGIA}

crença em Deus, divino, energia e/ou transcendência e, de modo geral, a religiosidade e a religião institucionalizada. Embora o estudo não apresente dados sobre pertencimento religioso, os resultados indicam um perfil que tende a maior vinculação a uma religiosidade pessoal e/ou institucional. Sobre a relação entre formação em Psicologia e espiritualidade, mais de $90 \%$ dos EP de ambos os cursos afırmam ser importante a discussão da temática na graduação. As justificativas salientam a noção de religião e espiritualidade como uma dimensão humana e seu papel nas diferenças socioculturais; o interesse por uma compreensão psicológica da espiritualidade; e sua relevância para o preparo ético e profissional. Na IES confessional, 80,9\% dos formandos responderam ter estudado o tema em uma disciplina da grade obrigatória que discute ciência e fé, bem como em eventos e palestras sobre a laicidade da psicologia e nos contextos de estágio e formação clínica. $\mathrm{Na}$ perspectiva desses colaboradores, a disciplina direcionada ao estudo da religião não aborda a temática da espiritualidade diretamente e a indicam como insuficiente, porém valorizam o espaço para conhecer diferentes religiões e o enfoque em discussões sobre tolerância, ética e moral. Na IES pública, $45 \%$ dos formandos responderam ter estudado sobre espiritualidade na graduação, indicando discussões em sala, orientação clínica e em disciplinas de filosofia, psicanálise, analítica, entre outras. Contudo, a análise sugere que tratar do assunto resume-se em tangenciar o tema em algumas disciplinas e contextos.

Com base na Psicologia Analítica, Nascimento (2017) analisou a perspectiva de professores-supervisores e estagiários de clínica sobre as diferenças entre religião, religiosidade e espiritualidade e identificou como principais símbolos do campo semântico: a) a religião como mito religioso, representação de caráter sagrado, rito e cerimônias com símbolos sagrados vinculados à totalidade do ser; b) religiosidade como voltada a rituais de instituições religiosas e vinculada à crença intrínseca e/ou extrínseca sobre a prática religiosa; e c) espiritualidade como busca individual pelo sagrado, independentemente da religião e da religiosidade; e os símbolos totalidade do ser, Deus e sagrado como passíveis de associação ao self ou ao centro de personalidade do indivíduo. A autora observa que nos três cursos o simbolismo acerca da psicoterapia na perspectiva dos estagiários se pauta na laicidade e que há uma interface maior entre psicologia, religião e religiosidade do que entre psicologia e espiritualidade. A relação entre religião do terapeuta e religião do paciente se mostra pautada no discurso, princípios e orientações dos Conselhos de Psicologia, no que tange ao privativo, ao que é proibido à prática, e à laicidade da psicologia. Sobre os contextos de intervenção na clínica psicológica, o tema religião é descrito
Karine Costa Lima Pereira e Adriano Furtado Holanda

como frequente na experiência dos estagiários; há uma preocupação iminente com a neutralidade e a ausência de julgamentos; a noção de que a religião pode ser prejudicial à saúde mental; e também o uso do conhecimento religioso pessoal e/ou oferecido pelo paciente para compreender as demandas de sentido.

\section{EIXOS TEMÁTICOS}

\section{Crenças pessoais, espiritualidade e saúde mental}

A maioria dos EP da amostra declara-se religiosa, com frequência maior de católicos, seguida de evangélicos e espíritas. Dentre os sem religião, a maioria descreve-se como espiritualizado ou crente em alguma forma de transcendente, com baixa representatividade de ateus nos estudos. A representação de Deus como Força, Energia ou Entidade Superior se destaca nos discursos de crentes e não crentes. A religião é definida como dimensão humana; crença em Deus ou como uma experiência emocional. A religiosidade aparece como experiência voltada à religião, que estrutura individualmente e socialmente essa dimensão. A espiritualidade, igualmente aparece como dimensão humana, e com frequência, como ligada ao indivíduo, à experiência individual com as crenças pessoais ou consigo mesmo, podendo ou não estar relacionada à religião institucionalizada ou à religiosidade. Os achados associados à saúde indicam escores altos de qualidade de vida e moderados de bem-estar espiritual; correlações significativas entre as dimensões qualidade de vida, bem-estar espiritual e atitude religiosa; e entre saúde mental e bem-estar espiritual.

\section{Ciência psicológica e religião: a psicologia explica}

Experiências de conflito e contradição com a relação entre crenças pessoais e ciência psicológica foram relatadas na maioria dos estudos. Tais vivências independem da religião de pertencimento ou tipo de crença, sendo mencionadas também por participantes sem religião. Os resultados indicam que os EP encontram dificuldades em relacionar experiências, dogmas e crenças com os conteúdos aprendidos no curso; podem modificar as formas de compreender e significar os fenômenos religiosos e as próprias vivências; e até mesmo romper com as crenças e/ou religião de origem.

Por outra via, os dados igualmente sugerem que a $E / R$ dos EP podem ajudar a ressignificar dissociações e conflitos, - que ocorre quando buscam assimilar conteúdos convergentes à fé, como na opção por abordagens psicológicas específicas, ou quando a psicologia se torna um instrumental colaborativo no desenvolvimento da espiritualidade pessoal. Tais resultados são equivalentes 


\section{-4: INTERACÃO EM LF PSICOLOGIA}

com os relatos de que psicologia e religião possuem objetivos comuns, e por isso podem atuar paralelamente ou, como observado nas vivências descritas inicialmente, de que se anulam mutuamente, não podendo ser articuladas. A relação, interesse ou opção por uma abordagem psicológica também pode compor essa problemática. Observa-se a busca por linhas teóricas compatíveis com as crenças ou não crenças e que o estudo da Psicanálise pode estar associado à vivência de conflito e menor bem-estar espiritual.

\section{Universidade e sala de aula}

Todos os estudos qualitativos observaram o discurso de que há um distanciamento entre psicologia e religião no ambiente acadêmico e de que temas relacionados não são abordados na graduação. Relatam sentir desconforto e constrangimento ao expor suas crenças pessoais no espaço universitário e entre seus colegas. Outra estrutura recorrente é a menção sobre a posição dos professores e supervisores de estágio clínico sobre a religião e a espiritualidade humana. Os EP relatam com frequência o modo como os docentes tratam o assunto e acabam por interferir na articulação entre a vivência de $E / R$ dos alunos e os conteúdos da psicologia. $A$ crítica na maioria dos relatos se refere a um posicionamento interpretado como negativo, quando os professores veiculam visões contraproducentes sobre essa faceta da experiência humana ou simplesmente se calam, não ensejando o diálogo.

No contexto das IES confessionais, observou-se o indicativo por parte dos EP de que as disciplinas de religião ofertadas na grade obrigatória contribuem com conhecimentos sobre as religiões e religiosidades, com uma visão mais ampla e ética sobre essa esfera do humano. Disciplinas voltadas ao estudo da experiência religiosa e/ou provenientes da Psicologia da Religião e da Espiritualidade não foram mencionadas nos resultados de nenhum dos estudos.

\section{Profissão e ética: a neutralidade na prática}

A maioria dos formandos da amostra já se havia deparado com o tema em seus atendimentos clínicos como estagiários. Observa-se, ainda que por menções bastante simplistas, que os EP avaliam a E/R como uma dimensão importante na vida de seus pacientes, que compõe a totalidade ou a cultura humana e que pode apresentar-se tanto de forma positiva quanto negativa. A menção de dificuldade, insegurança, preocupação e medo quando o assunto aparece na clínica evidencia-se nos resultados dos estudos qualitativos. Os relatos incluem questionamentos sobre a postura ética adequada (escuta e integralidade do sujeito versus neutralidade do terapeuta); medo de influenciar
Karine Costa Lima Pereira e Adriano Furtado Holanda

o paciente, revelar a religião pessoal e não saber lidar com suas próprias crenças; falta de conhecimento e manejo teórico-clínico; e dificuldade ou impedimento de abordar tais questões nas supervisões.

\section{DISCUSSÃO}

Nesta revisão, foram apresentados os principais resultados de 11 pesquisas realizadas com graduandos de psicologia sobre a relação entre suas vivências de $E / R$ e a formação de psicólogo. Ainda que os resultados desses estudos não possam ser generalizados para toda uma população de EP, a extensão da amostra estudada permite identificar vivências e percepções contínuas; conflitos, dificuldades; e preocupações comuns a EP de diferentes regiões do Brasil. A carência de estudos, e consequente discussão a respeito dos problemas e desafios apresentados, evidenciam-se tanto no número escasso de artigos quanto na representatividade das teses e dissertações observada nesta revisão. Embora quase a totalidade dessas últimas não esteja publicada em formato de artigo, o que ampliaria as possibilidades de divulgação e debate, ressalta o interesse e inquietação de psicólogos ao se voltarem para assuntos pertinentes à formação no contexto da pós-graduação.

Também se destaca a importância das IES confessionais e a pequena representação das IES públicas no desenvolvimento desses estudos. Tais resultados condizem com o papel histórico das instituições de confissão católica na disseminação da PR no país (Paiva et al., 2009), ainda que as Universidades públicas apareçam como primeiras colocadas no ranking de publicações em saúde e $E / R$ (Moreira-Almeida \& Lucchetti, 2016). Por outra via, essa diferença também atesta a crítica de Marques (2013) sobre a condição de distanciamento das IES brasileiras, especialmente as públicas, para com a dimensão espiritual dos estudantes universitários. Nesse sentido, evidenciam-se os resultados encontrados por Cavalheiro (2010)nos grupos focais com formandos de instituição pública e confessional, quando os primeiros, além de apresentarem os menores índices de bem-estar espiritual entre EP de todo o Estado do Rio Grande do Sul, sugerem uma perspectiva bastante limitada sobre a relação da psicologia com a religião e da espiritualidade humana com a saúde física e mental.

Embora parte representativa dos estudos não apresente dados sobre pertencimento religioso, observa-se um perfil de estudante que afirma possuir religião, resultado que condiz com as características apresentadas pelo Censo 2010 sobre a autodeclaração de religião ou culto do jovem brasileiro, quando cerca de $90 \%$ da população na faixa etária entre 15 e 24 anos respondem pertencer a alguma religião (IBGE, 2010). 


\section{WIIITERACÃO EM ET. PSICOLOGIA}

Karine Costa Lima Pereira e Adriano Furtado Holanda

Sob o mesmo prisma, estudos recentes realizados com estudantes da área da saúde, como enfermagem, medicina, biomedicina, terapia ocupacional e fisioterapia, indicam uma população também religiosa, que declara pertencer e praticar atividades religiosas ou acreditar em Deus (Espinha, Camargo, Silva, Pavelqueires \& Lucchetti, 2013; Lucchetti, Oliveira, Koenig, Leite \&Lucchetti, 2013;Zanetti, Lemos, Gotti, Tomé, Silva,\& Rezende, 2018). A importância e representação da religião e da espiritualidade na história de vida do jovem brasileiro (Novaes, 2013), e consequentemente daqueles que escolhem a profissão de psicólogo ainda nesta fase da vida, já legitima a crítica e o valor da discussão sobre a pertinência do tema religião e espiritualidade na graduação.

Os resultados relacionados à saúde e à qualidade de vida se assemelham aos estudos que apontam associação positiva dessas dimensões com a E/R (Koenig, 2012) e remetem a sua importância na saúde mental de jovens universitários como fator de proteção para transtornos mentais e sofrimento psíquico (Carlotto, 2013). Quanto aos índices pontuados na EBE, a incidência de escores moderados de bem-estar espiritual nos quatro estudos chama atenção quando comparados a pesquisas realizadas com outros estudantes universitários (Volcan et al., 2003) e com estudantes e profissionais da área da saúde (Pedrão \& Beresin, 2010; Silva, Souza, Nogueira, Moreira \& Chaves, 2013). Os EP tendem a ter escores menores; e formandos podem apresentar níveis ainda mais baixos de bem-estar espiritual que calouros. Lévano (2012) encontrou resultados equivalentes em estudo transcultural com EP de primeiro ano no Peru, República Dominicana, Bolívia e Argentina, com escores moderados de bem-estar espiritual nos três primeiros países e escores baixos para EP argentinos.

Os resultados sinalizam tanto para características peculiares à ciência psicológica e às ciências humanas como um todo, quanto para possíveis influências do curso de psicologia nas crenças e espiritualidade dos EP. Fica evidente que a relação complexa da psicologia com a religião e as consequentes limitações e insuficiências da formação podem favorecer o declínio do sentido positivo de bem-estar espiritual daqueles que adentram este campo. Corrobora com essa argumentação o indicativo de que a Psicanálise está associada a níveis ainda menores de bem-estar espiritual e a vivências de conflito; e à histórica patologização e reducionismo da experiência religiosa, amplamente disseminada por uma psicologia do senso comum², mas ainda presente nas salas de aula dos cursos do país
(Neubern, 2013).

No âmbito da relação formação científica versus crenças espirituais/religiosas, evidenciam-se nos resultados experiências de conflito e dificuldades encontradas pelos EP na dimensão pessoal e na esfera do preparo profissional. A busca por referenciais compatíveis com as crenças ou não crenças, ou mesmo por aqueles mais "científicos", parece sinalizar para um nível não apenas de conflito, mas de uma confusão conceitual a respeito de planos devidamente distintos como os da religião e da racionalidade científica. Como coloca Freitas (2007), a percepção de uma rivalidade entre os saberes científico e religioso durante os anos de curso gera impactos subjetivos, afetivos e cognitivos, que se expressam no conflito intrapessoal entre a experiência religiosa e a psicologia; na insegurança ou dúvida entre a explicação científica ou espiritual para fenômenos antes compreendidos como da ordem do religioso; na preocupação ética em relação à própria postura profissional diante de futuros pacientes religiosos ou ateus; e no conflito interpessoal com professores, colegas e familiares.

Conforme os resultados observados na revisão, as dificuldades e contradições vividas na formação científica desembocam na realidade da prática profissional dos EP. As experiências mostram futuros psicólogos que compreendem a importância da espiritualidade humana, mas guardam importantes questionamentos sobre seu fazer, sentem medo e insegurança. Assim como na sala de aula, não sabem ao certo o que farão com sua E/R na clínica, nem mesmo com a de seus pacientes. Nesse cenário, colocam em prática o que aprenderam: o silêncio e a esquiva, ou, dito de outra forma, a neutralidade - noção absolutamente discutível e criticada pelas epistemologias contemporâneas. Embora esse seja o discurso mais presente, diferentemente, alguns EP parecem admitir o valor e os benefícios de sua espiritualidade no acolhimento e escuta, quando tendem a usar mais seus conhecimentos e experiências espirituais/religiosas para compreender seus pacientes, visto que mantiveram em aberto, até o momento do estágio, as dificuldades subjetivas e cognitivas em assimilar a relação das teorias psicológicas com a experiência religiosa. Estudantes de enfermagem e medicina também relatam se sentirem inseguros diante da tarefa de abordar ou acolher uma demanda religiosa, por terem medo de influenciar o paciente com suas próprias crenças, por falta de conhecimento ou por não se sentirem preparados (Espinha et al., 2013; Lucchetti et al., 2013). Poucos estudantes desse grupo respondem recorrer à

2 Como psicologia do senso comum, nos referimos aqui a enunciados, pré-conceitos ou mesmo chavões que circulam em salas de aula, corredores e meios relacionadas à psicologia. Enunciados como "Deus está morto" e "religião é neurose obsessiva" que, embora tenham origem em teóricos e textos clássicos da filosofia e da psicologia, raramente são estudados em profundidade seja por estudantes, ou mesmo por muitos professores. Dada a frequência com que são repetidos, rapidamente se tornam "verdades", assim como no meio popular, de onde provém o que nós do meio científico discriminamos e denominamos senso comum. 


\section{W INERACÄOEM ET PSICOLOGIA}

literatura científica para buscar conhecimentos sobre a relação entre espiritualidade e saúde, e um número representativo deles afirma buscar esses conhecimentos dentro de sua própria religião.

A crise subjetiva vivenciada pelos EP necessariamente não deve ser interpretada como um problema, visto que tais experiências fazem parte do desenvolvimento pessoal, psicológico e religioso, especialmente quando se trata de novos conhecimentos e experiências, - estejam elas relacionadas à ciência, à fé ou à história de vida da pessoa. Como argumenta Freitas (2007), é desejável que se desenvolva no estudante a capacidade de revisão crítica e ética de pressupostos dogmáticos, num nível que contribua para sua formação profissional como psicólogo, sem que essa revisão seja confundida e sujeitada por um cientificismo ideológico ou defensivo, entretanto.

É nesse sentido último que se assenta a problemática mais inquietante encontrada nos resultados desta revisão e já anteriormente apontada por outros pesquisadores (AnconaLopez, 2005; Paiva, 2017a; Pereira \& Holanda, 2016),- o distanciamento e silenciamento do tema religião durante os anos de formação do psicólogo. Participantes em todos os estudos qualitativos, e também no levantamento realizado porVieira et al. (2013), relataram experienciar essa realidade no curso. Diante deste cenário, questiona-se, sobretudo, a natureza de uma psicologia que não escuta e silencia, não acolhe subjetividades e mesmo pessoas. Questiona-se o tipo de ciência, que por ainda parecer requerer seu lugar e distinção da religião, se ausenta e recusa investigar um fenômeno elementar de seu objeto, precavendo-se,assim, da irracionalidade e do intangível do ser religioso.

Como sugestão de novos estudos, destaca-se a importância de levantamentos multicêntricos, como os desenvolvidos por Espinha et al. (2013) e Lucchetti et al. (2013) na enfermagem e medicina, respectivamente, com enfoque nas especificidades da formação em psicologia, mas também, como nesses estudos, na relação entre a atuação profissional em saúde e a interface com E/R dos pacientes. Avalia-se também a importância de estudos de base qualitativa e quantitativa que explorem como EP compreendem e conceituam os termos religião, espiritualidade e religiosidade, tema abordado diretamente por apenas um dos estudos revisados. Estudos longitudinais ou transversais com calouros e formandos que investiguem as possíveis mudanças e influências da formação nas crenças espirituais/religiosas e na relação institucional com as religiões de origem dos EP; e, na mesma linha, investigações sobre possíveis diferenças na formação de acadêmicos de IES públicas, privadas e confessionais, dado as peculiaridades e diferenças ideológicas e políticas dessas instituições. Por fim, sugere-se o desenvolvimento de

\section{Karine Costa Lima Pereira e Adriano Furtado Holanda}

revisões de literatura como esta, que contemplem a literatura internacional sobre o eixo formação do psicólogo, religião e espiritualidade, e textos teórico-críticos, que objetivem ampliar as reflexões, discussões e as possíveis saídas para o problema aqui explorado.

\section{REFERÊNCIAS}

Ancona-Lopez, M. (2005). A espiritualidade e os psicólogos. In M. M. Amatuzzi (Ed.). Psicologia e Espiritualidade (pp. 147-159). São Paulo, SP: Paulus.

Ancona-Lopez, M. (2007). As crenças pessoais e os clínicos: orientação de dissertações e teses em Psicologia da Religião. In I. G. Arcuri\& M. Ancona-Lopez (Eds.), Temas em Psicologia da Religião (pp. 187-2010). São Paulo, SP: Vetor.

Ancona-Lopez, M. (2008). Religião na constituição da subjetividade: psicólogos e seus clientes. In V. A. Angerami (Ed.), Psicologia e Religião (p. 69-102). São Paulo: Cengage Learning.

Belzen, J. A. (2009). Psicologia Cultural da Religião: perspectivas, desafios, possibilidades. REVER - Revista de Estudos da Religião, 4, 1-29. Retirado de http://pucsp.br/ rever/rv4_2009/t_belzen.pdf

Carlotto, R. C. (2013). Espiritualidade e sintomatologia depressiva em estudantes universitários brasileiros. Revista de Psicologia da UNESP, 12(2), 50-60. Retirado de http://pepsic.bvsalud.org/pdf/revpsico/v12n2/a04.pdf

Carneiro, J. D. G. (2008). Experiência espiritual e psicopatologia: a percepção de professores de psicopatologia. Trabalho de Conclusão de Curso não publicado, Universidade Católica de Brasília, Brasília, DF, Brasil.

Cavalheiro, C. M. F. (2010). Espiritualidade na clínica psicológica: um olhar sobre a formação acadêmica no Rio Grande do Sul. Dissertação de Mestrado, Universidade do Vale do Rio dos Sinos, São Leopoldo, RS, Brasil). Retirado dehttp://www.repositorio.jesuita.org.br/handle/UNISINOS/ 2909

Costa, C. C. da, Bastiani, M. de, Geyer, J. G., Calvetti, P. Ü., Muller, M. C. \& Moraes, M. L. A. de. (2008). Qualidade de vida e bem-estar espiritual em universitários de psicologia. Psicologia em Estudo, 13(2), 249-255. doi: https://doi.org/10.1590/S1413-73722008000200007

Costa, W., Nogueira, C. \& Freire, T. (2010). The lack of teaching/study of religiosity/spirituality in psychology degree courses in Brazil: The need for reflection. Journal of Religion and Health, 49(3), 322-332. doi: https://doi.org/ $10.1007 / \mathrm{s} 10943-009-9255-9$ 


\section{-4* INTERACÃO EM LF PSICOLOGIA}

Esperandio, M. R. G. \& August, H. (2017). A pesquisa quantitativa em Psicologia da Religião no Brasil. Revista Pistis\&Praxis: Teologia e Pastoral, 9(1), 49-67. doi: https:// doi.org/http://dx.doi.org/10.7213/21751838.09.001.DS03

Esperandio, M. R. G. \& Marques, L. F. (2015). The Psychology of Religion in Brazil. International Journal for the Psychology of Religion, 25(4), 255-271. doi: https://doi.org/ 10.1080/10508619.2014.952189

Espinha, D. C. M., Camargo, S. M. de, Silva, S. P. Z.,Pavelqueires, S. \& Lucchettie, G. (2013). Opinião dos estudantes de enfermagem sobre saúde, espiritualidade e Religiosidade. Revista Gaúcha de Enfermagem, 34(4), 98106. doi: https://doi.org/10.1590/S1983 1447201300040001

Esteves, M. C. S. (2009). Os significados da religiosidade para docentes supervisores do curso de Psicologia. Tese de Doutorado, Pontifícia Universidade Católica de São Paulo, SP, Brasil. Retirado de https://tede2.pucsp.br/handle/ handle/15832

Ferreti, M. L. C. (2010). Crenças religiosas entre estudantes de graduação em psicologia. Dissertação de Mestrado, Universidade Federal do Rio de Janeiro, RJ, Brasil. Retirado de http://www.nutes.ufrj.br/mestrado/arquivos/ dis.MaraFerretti.pdf

Freitas, M. H. de. (2002). Crença religiosa e personalidade em estudantes de psicologia: um estudo por meio do Questionário Pratt e do Método de Rorschach.Tese de Doutorado não publicada, Universidade de Brasília, Brasília, DF, Brasil

Freitas, M. H. de. (2007). Quando o silêncio transborda, "calaboca" já morreu: religiosidade, cientificidade e formação em psicologia. In M. H. de Freitas \& O. P. Pereira (Eds.), As vozes do silenciado: estudos nas fronteiras da antropologia, filosofia e psicologia (pp. 187-205). BrasíliaDF: Universa.

Freitas, M. H. de. (2012). Religiosidade na experiência de atuação psi: sintoma ou saúde? In M. H. de Freitas \& G. J. de Paiva (Eds.), Religiosidade e cultura contemporânea: desafios para psicologia (pp. 191-229). Brasília-DF: Universa.

Gandelman, T. C. (2013). A religiosidade e a espiritualidade dos alunos no curso de formação de psicólogo. Dissertação de Mestrado em Psicologia, Pontifícia Universidade Católica de São Paulo, São Paulo, SP, Brasil. Retirado de https://tede2.pucsp.br/handle/handle/15267

Gastaud, M. B., Souza, L. D. D. M., Braga, L., Horta, C. L., Oliveira, F. M. De, Sousa, P. L. R. \& Silva, R. A. Da. (2006). Bem-estar espiritual e transtornos psiquiátricos menores em estudantes de psicologia: estudo transversal. Revista de Psiquiatria do Rio Grande do Sul, 28(1), 12-18. doi: https://doi.org/10.1590/S0101-81082006000100003
Karine Costa Lima Pereira e Adriano Furtado Holanda

Instituto Brasileiro de Geografia e Estatística. (2010). Censo Demográfico 2010: características gerais da população, religião e pessoas com deficiência. Rio de Janeiro. Retirado de http://www.ibge.gov.br

Koenig, H. G. (2012). Religion, Spirituality, and Health: The Research and Clinical Implications. International Scholarly Research Network - ISRN Psychiatry, 2012, não paginado; ID 278730. doi: http://dx.doi.org/10.5402/2012/278730

Lévano, A. C. S. (2012). Efectos del bienestar espiritual sobre la resiliencia en estudiantes universitarios de Argentina, Bolivia, Perú y República Dominicana. Tese de Doutorado, Universidad Nacional Mayor de San Marcos, Lima, Perú. Retirado de http://cybertesis.unmsm.edu.pe/handle/ cybertesis/3293

Lucchetti, G., Oliveira, L. R. de, Koenig, H. G., Leite, J. R. \&Lucchetti, A. L. G. (2013). Medical students, spirituality and religiosity-results from the multicenter study SBRAME. BMC Medical Education, 13(1).doi: https:// doi.org/10.1186/1472-6920-13-162

Machado, A. R. (2009). Supervisões e temas da religião: experiência de acolhimento. Dissertação de Mestrado, Pontifícia Universidade Católica de São Paulo, São Paulo, SP, Brasil. Retirado de https://tede2.pucsp.br/handle/ handle/15925

Marques, L. F. (2013). Desafios da integração da espiritualidade no Ensino Superior. In M. H. de Freitas, G. J. de Paiva \& C. de Moraes (Eds.), Psicologia da Religião no mundo contemporâneo: desafios da interdisciplinaridade (pp. 219-240). Brasília-DF: EdUCB.

Moreira-Almeida, A., Koenig, H. G. \& Lucchetti, G. (2014). Clinical implications of spirituality to mental health: review of evidence and practical guidelines. Revista Brasileira de Psiquiatria, 36(2), 176-182. doi: https://doi.org/http:// dx.doi.org/10.1590/1516-4446-2013-1255

Moreira-Almeida, A. \&Lucchetti, G. (2016). Panorama das pesquisas em ciência, saúde e espiritualidade. Ciência \& Cultura, 68(2), 54-57. doi: https://doi.org/10.21800/231766602016000100016

Nascimento, A. K. da C. (2017). Religiosidade, espiritualidade e psicoterapia na formação acadêmica do psicólogo. Tese de Doutorado, Universidade Católica de Pernambuco, Recife, PE, Brasil. Retirado de http://www.unicap.br/tede// tde_busca/arquivo.php?codArquivo=1280

Neubern, M. da S. (2013). Psicoterapia e espiritualidade. Belo Horizonte, MG: Diamante.

Novaes, R. (2013). Jovens sem religião: sinais de outros tempos. In F. Teixeira \&R. Menezes (Eds.), Religiões em movimento: o Censo 2010 (pp. 175-190). Petrópolis, RJ: Vozes. 


\section{-4* INTERACÃO EM LF PSICOLOGIA}

Oliveira, G. G. \& Oliveira, A. M. de. (2012). Modernidade, (des)secularização e pós-secularismo nos debates atuais da sociologia da religião. Revista de Teologia e Ciências da Religião da UNICAP, 1(1), 24-45. Retirado de http:// www.unicap.br/ojs/index.php/theo/article/view/109/216

Oliveira, M. P. de. (2010). Líderes religiosos cristãos e a formação em psicologia: os significados da busca pela formação em psicologia e seus efeitos na prática eclesiástica. Dissertação de Mestrado, Pontifícia Universidade Católica de São Paulo, SP, BrasilUCSP. Retirado de https://tede2.pucsp.br/handle/handle/14991

Paiva, G. J. de, Zangari, W., Verdade, M. M., Paula, J. R. M. de, Faria, D. G. R. de, Gomes, D. M., ... Gomes, A. M. de A. (2009). Psicologia da Religião no Brasil: a produção em periódicos e livros. Psicologia: Teoria e Pesquisa, 25(3), 441-446. doi: https://doi.org/10.1590/S010237722009000300019

Paiva, G. J. de. (2017a). InvitedPaper - Um passo atrás: minha caminhada em Psicologia da Religião. REVER Revista de Estudos da Religião, 17(1), 10-17. doi: https:// doi.org/10.23925/1677-1222.2017vol17i1a2

Paiva, G. J. de. (2017b). Psicologia acadêmica da religião no Brasil: história, resultados e perspectivas. Revista Pistis\&Praxis: Teologia e Pastoral, 9(1), 31-48. doi: https:// doi.org/10.7213/2175-1838.09.001.DS02

Paloutzian, R. F. \&Elisson, C. W. (1982).Loneliness, spiritual well-being and the quality of life.In L. A. Peplau\& D. Perlman (Eds.), Loneliness: a sourcebook of current theory, research and therapy (pp. 224-237). Nova York, US: Wiley.

Paloutzian, R. F. (2017). Psychology of Religion in the World. Revista Pistis\&Praxis: Teologia e Pastoral, 9(1), 15. doi: https://doi.org/10.7213/2175-1838.09.001.DS01

Pedrão, R. B. \& Beresin, R. (2010). O enfermeiro frente à questão da espiritualidade. Einstein, 8(1), 86-91. Retirado de http://apps.einstein.br/revista/arquivos/PDF/1208Einsteinv8n1_p86-91_port.pdf

Pereira, K. C. L. \& Holanda, A. F. (2016). Espiritualidade e religiosidade para estudantes de psicologia: ambivalências e expressões do vivido. Revista Pistis\&Praxis: Teologia e Pastoral, 8(2), 385-413. doi: https://doi.org/10.7213/revistapistispraxis.08.002.DS07

Piasson, D. L. (2017). O Senso Religioso na formação em psicologia no Brasil: uma análise dos currículos universitários. Dissertação de Mestrado em Psicologia, Universidade Católica de Brasília, Brasília, DF, Brasil. Retirado de https://bdtd.ucb.br:8443/jspui/handle/tede/ 2330
Pinho, R. B. de S. (2012). Crenças religiosas e conhecimento psicológico na perspectiva do aluno do curso de psicologia. Dissertação de Mestrado em Psicologia, Pontifícia Universidade Católica de São Paulo, São Paulo, SP, Brasil. Retirado de https://tede2.pucsp.br/handle/ handle/15114

Silva, A. F. S. (2010). Conexões e distinções entre experiências e psicopatologia na percepção de psicólogos recém-formados. Trabalho de Conclusão de Curso não publicado, Universidade Católica de Brasília, Brasília, DF, Brasil.

Silva, L. A. C. da. (2016). Espiritualidades e Bem-estar Espiritual no processo formativo de estudantes de psicologia do Recife/PE à luz da Abordagem Integral/ Transpessoal. Dissertação de Mestrado em Educação, Universidade Federal de Pernambuco, Recife, PE, Brasil. Retirado de http://repositorio.ufpe.br/handle/ $123456789 / 18066$

Silva, R. de P., de Souza, P., Nogueira, D. A., Moreira, D. da S. \& Chaves, E. de C. L. (2013). Relação entre bem-estar espiritual, características sociodemográficas e consume de álcool e outras drogas por estudantes. Jornal Brasileiro de Psiquiatria, 62(3), 191-198. doi: https://doi.org/ 10.1590/S0047-20852013000300003

Souza, F. F. de. (2014). Psicologia e espiritualidade - grupo temático com alunos adventistas de graduação em psicologia. Dissertação de Mestrado, Pontifícia Universidade Católica de São Paulo, São Paulo, SP, Brasil. Retirado de https://tede2.pucsp.br/handle/handle/15381

Volcan, S. M. A., Sousa, P. L. R., Mari, J. de J. \& Horta, B. L. (2003). Relação entre bem-estar espiritual e transtornos psiquiátricos menores: estudo transversal. Revista de Saúde Pública, 37(4), 440-445. doi: https://doi.org/ 10.1590/S0034-89102003000400008

Vieira, T. M., Zanini, D. S. \& Amorim, A. de P. (2013). Religiosidade e Bem-Estar Psicológico de Acadêmicos de Psicologia. Interação em Psicologia, 17(2), 141-151. doi: https://doi.org/http://dx.doi.org/10.5380/psi.v17i2.26678

Zanetti, G. C., Lemos, G. L., Gotti, E. S., Tomé, J. M., Silva, A. P. da \& Rezende, E. A. M. R. de. (2018). Percepção de acadêmicos de medicina e de outras áreas da Saúde e Humanas (ligadas à Saúde) sobre as relações entre espiritualidade, religiosidade e saúde. Revista Brasileira de Educação Médica, 42(1), 65-72. doi: https://doi.org/http:// dx.doi.org/10.1590/1981-52712018v42n1rb20160044

Recebido em 13.03.2019 Primeira Decisão Editorial em 15.04.2019 Aceito em 02.05.2019 